\title{
FORMULATION OF LOTION FROM BLACK TEA EXTRACT (CAMELLIA SINENSIS LINNAEUS) AS SUNSCREEN
}

\section{IYAN SOPYAN ${ }^{1,2}$, RIESTYA DWI PERMATA ${ }^{1}$, DOLIH GOZALI ${ }^{1,2}$, INSAN SUNAN KURNIAWAN SYAH ${ }^{2}$}

1Pusdi Drug Delivery and Drug Disposition, Faculty of Pharmacy, Universitas Padjadjaran, Bandung, Indonesia, ${ }^{2}$ Departement of Pharmaceutics and Technology of Formulation, Faculty of pharmacy, Universitas Padjadjaran, Bandung, Indonesia Email: i.sopyan@unpad.ac.id

Received: 06 Sep 2018, Revised and Accepted: 14 Dec 2018

\section{ABSTRACT}

Objective: The goal of the project was to explore extracts from black tea leaves (Camellia sinensis Linnaeus) to prove it can give protection against ultraviolet rays (UV) in lotion preparation.

Methods: Black tea extract was made in sunscreen lotion in oil in water (O/W) type emulsion using a combination of PEG-8 and beeswax as emulsifying agent 1, and combination of cetyl alcohol, ceteth-20, and steareth-20 as emulsifying agent 2 . Evaluation of lotion including phytochemical screening of black tea leaf extract, measurement of sun protecting factor (SPF) value of extract black tea leaves, measurement of SPF preparation lotion sunscreen extract black tea leaves, physical observation of preparation, qualitative preparation evaluation using thin layer chromatography (TLC) and lotion security testing have been done to ensure the quality of lotions.

Results: The result exhibited the effective SPF that was different to the sunscreen lotion F1, which contained $0.03 \% \mathrm{w} / \mathrm{v}$ and F2 which contain of $0.04 \% \mathrm{w} / \mathrm{v}$ black tea leaves extract with the point of SPF is 20.31 and 24.71 respectively. Both formulas fulfilled the requirements as lotion preparations and did not irritate the skin based on an irritation test on 20 volunteers.

Conclusion: Formulas F1 and F2 can be applied as a sunscreen with good physical quality and is safe for topical use in lotion preparation.

Keywords: Lotion, Sunscreen, SPF, Black tea leaf extract

(c) 2019 The Authors. Published by Innovare Academic Sciences Pvt Ltd. This is an open-access article under the CC BY license (http://creativecommons.org/licenses/by/4.0/) DOI: http://dx.doi.org/10.22159/ijap.2019v11i1.29564

\section{INTRODUCTION}

In recent years, the incidence of various diseases and disorders associated with solar ultraviolet radiation has increased, and it continues to grow [1]. Chronic exposure to mammalian skin by UV radiation causes a number of biological responses, including the development of erythema, edema, and formation of skin burn cells, immune suppression, DNA damage, photoaging, and melanogenesis. These changes are directly or indirectly involved in the development of skin cancer $[1,2]$. Although naturally human skin already has a protective system against the effects of harmful sunlight, it is not yet effective enough to overcome excessive radiation. For that purpose, because Indonesia is a tropical country that is sunlight throughout the year, it is necessary to have additional protection, both physically and chemically, the latter of which is by using sunscreen [3].

Daily use of sunscreen is an important addition for skin protection [4]. Sunscreen is a cosmetic preparation that can be used to blend or absorb sunlight effectively. Therefore, this sunscreen can prevent the occurrence of skin disorders due to solar radiation [5]. A lotion is a liquid preparation intended for external use on the skin and used as a protective, or for medication due to the nature of the ingredients, such as antioxidant preparation $[4,6,7]$.

Previous studies indicated water extracts and alcohol extracts of black tea (Camelia sinensis Linn.) were tested in vitro to see its absorption activity against ultraviolet (UV) light waves. From the results of the study, it was found that both extracts showed UV absorption with the same treatment. Black tea leaf extract is then made in gels form and re-tested for its absorption against exposure to ultraviolet rays. As a result, black tea leaf gels to provide protection for the skin against wavelengths of 200-400 nm characterized by the absence of erythema, can be used safely in large quantities of the skin surface without any toxicological concerns [8]. Based on these results, the extract of black tea leaves (Camellia sinensis L.) was formulated in other dosage forms, which are more widely used as topical preparations such as lotions with more than a gel. The aim of this study, using a sunscreen preparation was to explore the potential of tea leaf extract as effective, stable and safe preparation for use as a sunscreen lotion.

\section{MATERIALS AND METHODS}

\section{Materials}

Black tea leaf extract (Camellia sinensisLinnaeus) obtained from PT. Lansida herbs (Yogyakata, certified). PEG-8 (Gattefosse $®$ ), beeswax (Gattefosse ${ }^{\circledR}$, Bratachem), cetylalcohol (Gattefosse, Bratachem), ceteth-20 (Gattefosse $\left.{ }^{\circledR}\right), \quad$ steareth-20 (Gattefosse $\AA$ ) paraffin liquidum (Quadrant), methylparaben (Bratachem), propylparaben (Bratachem), ethanol 96\% (Merck), ethanol 70\% (Merck).

\section{Tool}

A set spectrophotometer UV-Vis (Analytical zena, Specord 200), viscometer (Brookfield DV II+pro), water bath (Memmerth), centrifugation device (Hetticheba 20), homogenizer, optical microscope (Zeus), analytical balance (Ohaus), and digital pH meters (Methroom type 744).

\section{Methods}

\section{Preparation of extract}

Extract of black tea leaves (Camellia sinensis Linnaeus) that have met the requirements and standards of Herbal Pharmacopoeia and MMI obtained from PT. Lansida Herbal in (Yogyakarta). PT. Lansida Herbal obtained processed leaf tea from the Temanggung area (Central Java) which had previously been determined.

Phytochemical screening of black tea leaf extract (Camellia sinensis Linnaeus)

Extracts from black tea leave (Camellia sinensis Linnaeus) obtained are examined for their content by examination such as alkaloid compounds, polyphenols, flavonoids, monoterpenoids, sesquiterpenoids, steroids, triterpenoids, tannins, saponins, and quinones using special chemical reagents [8]. 
Measurement of sun protecting factor (SPF) value of extract black tea leaves (Camellia sinensis Linnaeus)

Three concentrations of extract solution of black tea leaf $(0.01 \%$, $0.015 \%, 0.02 \%$ ) were prepared for $96 \%$ ethanol solvent. Each sample of the extract solution was measured uptake by using a UVVis spectrophotometer to produce a spectrum or curve. Furthermore, the area under the curve is calculated every $5 \mathrm{~nm}$ of the absorption number of the nth wavelength and absorption at the wavelength (n-1) divided by 2 times 5 (trapezoidal area). Calculate SPF log value by dividing the total area under the curve by the largest and smallest wavelength difference. Next, the SPF log value is changed into SPF $[9,10]$. The calculation of SPF is done in the following way:

$$
=\log _{10} \mathrm{SPF}
$$

\section{Selection of lotion bases}

Prepared of three lotion basis formulas for variation in emulsifying agent 1 (PEG-8 and Beeswax) 3\%, 4\%, and 5\% w/v. Emulsifying agent into the oil phase (paraffin liquidum), then melted over the water bath at $70{ }^{\circ} \mathrm{C}-80{ }^{\circ} \mathrm{C}$. Aquadestillata is heated at $70{ }^{\circ} \mathrm{C}-80{ }^{\circ} \mathrm{C}$ as a water phase, afterward, mix the oil phase into the water phase and stir until homogeneous and form the preparation lotion.

\section{Formulation of a sunscreen lotion from extract black tea leave} (Camellia sinensis Linnaeus)

Preparation lotion sunscreen is made with the addition of extract concentration of black tea leaves (the measured SPF 15 extract) bit by bit into the lotion base which has the best physical outcome of base orientation and stirred to form a good and homogeneous lotion.

\section{Measurement of SPF preparation sunscreen lotion from extract} black tea leaves (Camellia Sinensis Linnaeus)

Preparation of lotions containing extract concentration of black tea leaves was dissolved in $96 \%$ ethanol with a base and solvent ratio of 1:4 and heated over a stirred bath until homogeny. After being centrifuged for ten minutes, the filtrate in the solution was pipetted and measured uptake using UV-Vis spectrophotometry at a wavelength of 280-320 nm to produce a spectrum or curve. Base on the curve is calculated SPF value.

\section{Physical observation of lotion}

Physical observation of preparation lotion includes organoleptic observation, $\mathrm{pH}$ measurement, viscosity measurement, globule size measurement with freeze-thaw method and observation of the separation occurring in the preparation of sunscreen extract lots of black tea leaves using centrifugation method.
Evaluation of qualitative preparation using thin layer
chromatography (TLC)

Preparation lotions containing extracts from black tea leave and black tea leaf extracts were each tested qualitatively using TLC method to determine the presence of active compounds present in the preparation of the lotion by comparing the color of the spots and RF (range factor) to the black tea leaf extract. This TLC method uses silica gel as a stationary phase and the eluent developer as the mobile phase.

\section{Lotion security testing}

The safety test of a lotion with extract concentration of black tea leaf (F2) in the upper back using patch test method to preparation lotion was done by attaching the preparation lotion without extract of black tea leaf (F0) and sunscreen lotion that containing black tea leaves extract to 20 volunteers.

\section{RESULTS AND DISCUSSION}

Preparation of a black tea leaves extract (Camellia sinensis Linnaeus)

The result of a determination of black tea leaves plant used shows that: Simplicia has been determined in the pharmaceutical biology laboratory of the Gajah Mada University pharmacy faculty and obtained a certificate of determination with number BF/178/Ident/II/2011 (supplementary file) and it was confirmed as tea leaves simpilicia

\section{Phytochemical screening results of black tea leaves extract} (Camellia sinensis Linnaeus.)

Phytochemical screening of black tea leaves extracts resulted in several secondary metabolites compounds that have the potential antioxidants such as polyphenol, tannin, flavonoid, monoterpenoid, sesquiterpenoid. The most potent compound as an antioxidant is polyphenols. It's containing epigallocatechin (EGCG), and theaflavin have activity as a sunscreen with its properties that absorb ultraviolet light [3].

\section{Measurement of SPF value extract black tea leaves (Camellia} Sinensis Linnaeus)

The SPF value measurement results from the extract of black tea leaves were used as a baseline of the extract concentration to be used in the formulation preparation of sunscreen lotion. The following measurements of SPF values are extract concentration $(0.01 \%, 0.015 \%$, and $0.02 \%)$. The result of SPF extract of black tea leaves can be seen in table 1. It's has shown the three extract concentrations, the SPF approaching SPF 15 was at $0.02 \% \mathrm{w} / \mathrm{v}$ concentration and $0.02 \%$ extract concentration of black tea is used as a benchmark of concentration in formulation the preparation sunscreen. Selected close to SPF 15, since SPF 15 is the least effective SPF value to be able to protect the skin from UV by $95 \%[11,12]$.

Table 1: Results of SPF value measurement on black tea leaf extract $(n=3)$

\begin{tabular}{ll}
\hline Concentration of extract $(\% \mathbf{w} / \mathbf{v})$ & SPF value \pm SD \\
\hline 0.010 & $3.69 \pm 0.20$ \\
0.015 & $6.90 \pm 0.30$ \\
0.020 & $17.40 \pm 0.30$ \\
\hline
\end{tabular}

\section{Results of lotion bases selection}

The result of preparation of a lotion base can be seen in table 2 . The second formula (F2) was chosen due to the consistency of the solid was slightly easy to flow (table 3). Formulas 1 and 3 are not selected because the formula 1 preparation lotion is less dense and the formula 3 lotion is too dense [13]. Based on table 4, it appears that the three lotion formulas that were made did not change during $7 \mathrm{~d}$ of storage time.

Table 2: Lotion base formulation $(n=3)$

\begin{tabular}{|c|c|c|c|}
\hline \multirow[t]{2}{*}{ Material } & \multicolumn{3}{|c|}{ Formulation \% w/v } \\
\hline & 1 & 2 & 3 \\
\hline PEG-8, Beeswax (Emulsifying agent 1) & $3 \%$ & $4 \%$ & $5 \%$ \\
\hline Cetyl alcohol, Ceteth-20, Steareth-20 (Emulsifying agent 2) & $2 \%$ & $2 \%$ & $2 \%$ \\
\hline Parafin liquidum & $17 \%$ & $17 \%$ & $17 \%$ \\
\hline Metil paraben & $0.05 \%$ & $0.05 \%$ & $0.05 \%$ \\
\hline Propil paraben & $0.05 \%$ & $0.05 \%$ & $0.05 \%$ \\
\hline Water & Add $100 \%$ & Add $100 \%$ & Add $100 \%$ \\
\hline
\end{tabular}

F1: 2\% emulsifying agent 1 (PEG-8-Beeswax) (n=3), F2: 3\% emulsifying agent1 (PEG-8-Beeswax) (n=3), F3: 4\% emulsifying agent 1 (PEG-8-Beeswax) (n=3) 
Table 3: Result of preparation lotion bases $(n=3)$

\begin{tabular}{lll}
\hline Formulation & Colour & Viscosity \\
\hline F1 & white & light viscous \\
F2 & white & light viscous \\
F3 & white & viscous \\
\hline
\end{tabular}

F1: lotion with emulsifying agent PEG-8-beswax (3\%w/v) O/W, F2: lotion with emulsifying agent PEG-8-beswax (4\% w/v) 0/W, F3: lotion with emulsifying agent $1(5 \% \mathrm{w} / \mathrm{v}) \mathrm{O} / \mathrm{W}(\mathrm{o} / \mathrm{w}=$ oil in water emulsion type) $(\mathrm{n}=3)$.

Table 4: Observation results of physical changes of lotion bases for seven days ( $n=3)$

\begin{tabular}{|c|c|c|c|c|c|c|c|c|}
\hline \multirow[t]{2}{*}{ Formulation } & \multirow[t]{2}{*}{ Parameters } & \multicolumn{7}{|c|}{ Days } \\
\hline & & 1 & 2 & 3 & 4 & 5 & 6 & 7 \\
\hline \multirow[t]{2}{*}{ F1 } & Consitency & + & + & + & + & + & + & + \\
\hline & Colour & $\mathrm{w}$ & $\mathrm{w}$ & $\mathrm{w}$ & $\mathrm{w}$ & W & $\mathrm{w}$ & w \\
\hline \multirow[t]{2}{*}{$\mathrm{F} 2$} & Consitency & ++ & ++ & ++ & ++ & ++ & ++ & ++ \\
\hline & Colour & $\mathrm{w}$ & $\mathrm{w}$ & $\mathrm{w}$ & w & $\mathrm{W}$ & $\mathrm{w}$ & $\mathrm{w}$ \\
\hline \multirow[t]{2}{*}{ F3 } & Consitency & +++ & +++ & +++ & +++ & +++ & +++ & +++ \\
\hline & Colour & $\mathrm{w}$ & $\mathrm{w}$ & w & w & W & w & $\mathrm{w}$ \\
\hline
\end{tabular}

${ }^{*} \mathrm{~F} 1$ : The lotion formula with emulsifying agent concentration of $1,(3 \% \mathrm{w} / \mathrm{v})[\mathrm{O} / \mathrm{W}](\mathrm{n}=3),{ }^{*} \mathrm{~F} 2$ : The lotion formula with emulsifying agent concentration of $1,(4 \% \mathrm{w} / \mathrm{v})[\mathrm{O} \mathrm{W}](\mathrm{n}=3),{ }^{*} \mathrm{~F} 3$ : The lotion formula with emulsifying agent concentration of $1,(5 \% \mathrm{w} / \mathrm{v})[\mathrm{O} / \mathrm{W}](\mathrm{n}=3),{ }^{*} \mathrm{w}$ : white, ${ }^{*}+$ : less viscous,++: viscosus but easy to flow,+++: Viscous

Formulation preparation of lotion sunscreen extract black tea leaf (Camellia sinensis Linnaeus)

According to the result of orientation lotion base, this obtained some formulas of sunscreen lotion with the addition of extract of black tea leaves as presented in table 5. According to the observations, the addition of extract of black tea leaves changes the color of the lotion to light brownish yellow and changes the viscosity. Many extracts of black tea leaves are added to more dilute the lotions made.

Table 5: Sunscreen lotion formula with the addition of black tea extract $(n=3)$

\begin{tabular}{lll}
\hline Materials & Formulation (\% w/v) & \\
\cline { 2 - 3 } & F1 & F2 \\
\hline Extract black tea leaf & 0.03 & 0.04 \\
PEG-8-beeswax & 4 & 4 \\
Emulsifying agent & 2 & 2 \\
Parafin liquid & 17 & 17 \\
Methyl paraben & 0.05 & 0.05 \\
Prophyl paraben & 0.05 & 0.05 \\
Water & Add 100 & Add 100 \\
\hline
\end{tabular}

Notice, F1: lotion containing extract of black tea leaves $0.03 \% \mathrm{w} / \mathrm{v}, \mathrm{F} 2$ : lotion containing extract of black tea leaves $0.04 \% \mathrm{w} / \mathrm{v}$; no of experiment (n=3)

\section{Measurement of SPF lotion sunscreen extract black tea leaves (Camellia sinensis Linnaeus)}

For the measurement of SPF extract of black tea leaves, the formulation preparation sunscreen was prepared with two concentrations of $0.03 \% \mathrm{w} / \mathrm{v}$ and $0.04 \% \mathrm{w} / \mathrm{v}$. Both formulations remeasured SPF value 3 times the iteration. The results of SPF measurements on the preparation is exhibited in table 6. It is shown that the SPF value in the preparation extract of black tea has decreased compared to the SPF value of the black tea extract before it was added into the preparation lotion. This may be due to the influence of the base, which provides an interaction with the effectiveness of the preparation in UV absorption. In addition. Sample treatment for SPF measurements can also have an effect on decreasing SPF. The possibility of extract black tea in preparation lotion is not entirely interesting in the solvent upon extracting. However, despite the decline in SPF values, it is not significant or still tolerable. In addition. Table 4 also showed that F1 and F2 have an effective SPF value for use as a sunscreen because the SPF value is $>$ SPF $15[14,15]$.

Table 6: Results of formulation preparation lotion $(n=3)$

\begin{tabular}{lll}
\hline Formulation & Color & Viscosity \\
\hline F0 & White & thick \\
F1 & White & thick \\
F2 & White & thick \\
\hline
\end{tabular}

Number of experimen $=3$

Table 7: Results of SPF measurement $(n=3)$

\begin{tabular}{llll}
\hline Formulation & SPF Value \pm SD & & $\mathbf{3}$ \\
\cline { 2 - 4 } & $\mathbf{1}$ & $\mathbf{2}$ & $20.09 \pm 0.21$ \\
\hline F1 & $20.28 \pm 0.20$ & $20.55 \pm 0.20$ & $25.64 \pm 0.23$ \\
F2 & $23.54 \pm 0.25$ & $24.88 \pm 0.21$ & \\
\hline
\end{tabular}

${ }^{*} \mathrm{~F} 1$ : Lotion withblack tea extract $0.03 \% \mathrm{w} / \mathrm{v}(\mathrm{n}=3),{ }^{*} \mathrm{~F} 2$ : Lotion with black tea extract $0.04 \% \mathrm{w} / \mathrm{v}(\mathrm{n}=3)$ 


\section{Results of physical observation}

The results of physical observation of lotion included organoleptic observation including the $\mathrm{pH}$ (fig. 1), viscosity measurement (fig. 2) and observation of separation (fig. 3) occurring on the preparation of sunscreen of extract black tea leaves gives significant difference to the extraction of concentration of black tea leaves in preparation lotion for $28 \mathrm{~d}$ storage. Based on fig. 1, it can be seen that the three lotion formulas have a $\mathrm{pH}$ that tends to be acidic. This is due to the addition of extracts of black tea leaves that have an acidic $\mathrm{pH}$ during storage time. The $\mathrm{pH}$ of the three lotion formulas decreased. Changes that occurred in $\mathrm{pH}$ during storage can be caused by external and internal factors. External factors include temperature and humidity, while the internal factor is characteristic of the extract whose $\mathrm{pH}$ is already relatively acidic, but the $\mathrm{pH}$ preparation of the sunscreen lotion made still fall within the $\mathrm{pH}$ range for topical preparation ranging from 4 to 8 [15]. Based on the statistical calculations of the complete block design. $\mathrm{H}_{0}$ is rejected at $95 \%$ and $99 \%$ confidence level due to $\mathrm{F}_{\text {Calc }}>\mathrm{F}_{\text {Value }}$. It means that there is a significant difference of $\mathrm{pH}$ lotion due to the effect of black tea leaves extract concentration with $95 \%$ and $99 \%$ confidence level.

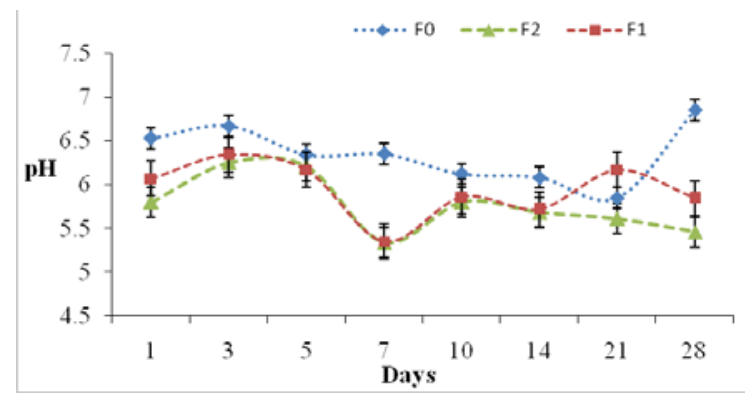

Fig. 1:Graph of average yield $\mathrm{pH}$ lotion, F0=---: lotion less extract black tea leaves; $F 1=--$-(lotion less extract black tea leaves $0.03 \% \mathrm{w} / \mathrm{v}$ );F2=---: (lotion less extract black tea leaves $0.04 \% \mathrm{w} / \mathrm{v})$ sunscreen for $28 \mathrm{~d}(\mathrm{n}=3)$

According to fig. 2, it can be seen that the viscosity of the three lotion formulas has changed during $28 \mathrm{~d}$ of storage. Changes were caused by several influential factors, such as changes in room temperature. Increased storage temperatures can disrupt the water phase and oil phase binding and also increase the dispersed phase globule motion. In addition, other factors that affect the viscosity of the lotion are $\mathrm{pH}$. The decrease in $\mathrm{pH}$ on the lotion causes a decrease in viscosity as well. It is also shown in the table that increasing the addition of the extract will decrease the viscosity [16], the good lotion has a viscosity of 500-5000cp [17]. Based on the statistical calculations of the complete block design, $\mathrm{HO}$ is rejected due to $\mathrm{P}_{\text {value }}>\mathrm{F}_{\text {Table }}$ with $95 \%$ and $99 \%$ confidence level. This means that there is a significant difference in viscosity of the lotion due to the effect of extracting the concentration of black tea leaves.

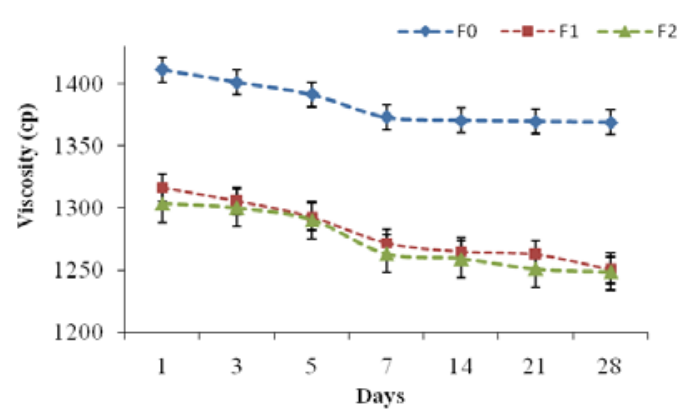

Fig. 2: Viscosity of sunscreen lotion in $28 \mathrm{~d}$. F0: lotion without extract leaves of black tea, $F_{0}$ : lotion without extract of black tea leaves, F1: lotion with extract of black tea leaves $0.03 \%$ F2: lotion with extract of black tea leaves $0.04 \% ;(n=3)$
Storage of lotions at two different temperatures or freeze-thaw cycles was conducted to see the effect of temperature on the separation of lotion (fig. 3). The freeze-thaw cycle is a freeze-melting cycle in which preparation is stored in a cycle between two temperatures of $4{ }^{\circ} \mathrm{C}$ and $40{ }^{\circ} \mathrm{C}$. These two temperatures are as close to realistic storage conditions on the shelves to prevent unwanted reactions. Based on statistical calculations of complete block design, $\mathrm{H}_{0}$ is rejected due to $\mathrm{F}_{\text {value }} \mathrm{F}_{\text {Table }}$ with $95 \%$ and $99 \%$ confidence level. This means that there is a significant difference in globular lotion size due to the effect of extracting the concentration of black tea leaves [18].

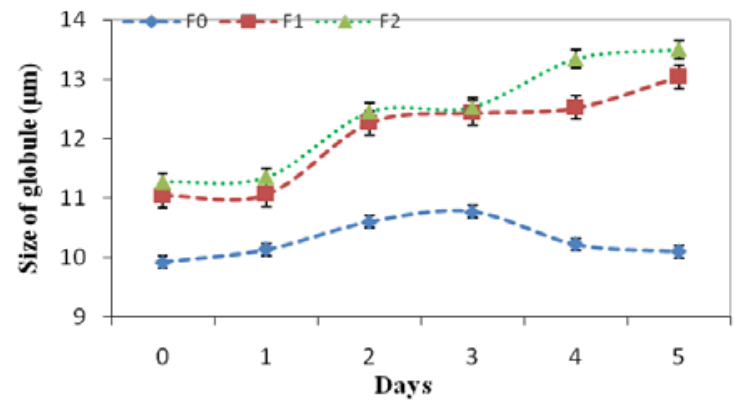

Fig. 3: Graph of average globul size of lotion over, $28 \mathrm{~d}$ storage $(n=3)$, F0: lotion without extract leaves of black tea, F1: lotion with extract of black tea leaves $0.03 \%$ F2: lotion with extract of black tea leaves $0.04 \% ;(n=3)$

Qualitative evaluation of preparation using thin layer chromatography

The result of thin layer chromatography of black tea extract leaf and preparation of black tea extract lotion can be seen in fig. 4. Extract of black tea leaves and preparation of sunscreen lotion containing extracts of black tea leaf was further observed by thin layer chromatography method to identify the active compound of polyphenols and to see the changes of the active compound components of extract and preparation. The results of the thin layer chromatography from black tea leaf extract and preparation of sunscreen lotion containing black tea extract were observed using UV $254 \mathrm{~nm}$ and UV $366 \mathrm{~nm}, \mathrm{FeCl}_{3}$ spotting appearance and the results showed the same pattern of spots and RF values on both suspected polyphenol compounds and, due to the color of the spots, the reaction product with $\mathrm{FeCl}_{3}$ is blackish black.

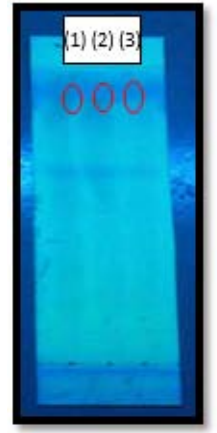

(a)



(b)

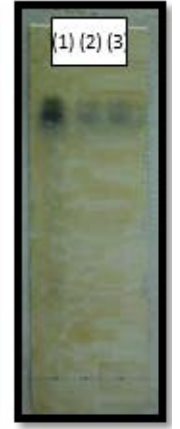

(c)
Fig. 4: Chromatogram of extract and preparation (1): extract black tea leaves; (2) sunscreen lotion $0.03 \%$ extract; black tea leaves, (3): sunscreen lotion $0.03 \%$ extract black tea leaves; (a): UV light 254 nm, (b): UV light $366 \mathrm{~nm}$, (c): using $\mathrm{FeCl}_{3}$

Fig. 4 showed the same pattern of spots and range factor values in both suspected polyphenol compounds because of the color of the 
spotting of the reaction with a blackish blue $\mathrm{FeCl}_{3}$. This showed no change in the active compound in the black tea extract and the preparation of black tea extract sunscreen lotion, which indicated a good quality of extract in sunscreen preparation [19].

\section{Lotion security testing}

Based on fig. 5, it can be seen that the preparation of lotion with extract leaves of black tea with a concentration of $0.041 \% \mathrm{w} / \mathrm{v}$ does not irritate the skin, which is indicated by the absence of heat reaction, redness and irritation or itching on the skin of the volunteers. This was not the case with preparation lotions without extract leaves of black tea (base lotion).



(a)

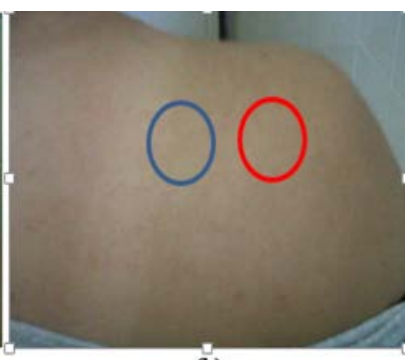

(b)
Fig. 5: Security test of sunscreen lotion of black tea leave extract : Basis Spread: : sunscreem lotion spread containing black tea extract, (a) before treatment, (b) After treatment (no of experiment $(n=20)$ )

\section{CONCLUSION}

It can be concluded that the extract of black tea leaves that has effectiveness as sunscreen is at a concentration of $0.02 \% \mathrm{w} / \mathrm{v}$ of the sunscreen lotion formulation. This is an effective lotion formulation as a sunscreen with F1 (0.03\% w/v extract black tea leaves) and F2 $(0.04 \% \mathrm{w} / \mathrm{v}$ extract black tea leaves), with SPF values of 20.31 and 24.71 respectively. Preparation of sunscreen lotion containing a mixture of emulsifying agent 1 (PEG-8-beeswax) and emulsifying agent 1 (mixture of ceteth and cetyl alcohol), paraffin liquidum, distilled water and methylparaben, prophylparaben as preservatives meet pharmaceutical requirements for a $28 \mathrm{~d}$ storage period. Based on an irritation test on 20 volunteers with open patch test, F1 and F2 sunscreen lotions do not irritate the skin. Therefore, preparation lotions with extract leaves of black tea with a concentration of $0.03 \%$ and $0.04 \% \mathrm{w} / \mathrm{v}$ can be applied as a sunscreen lotion and safely used topically.

\section{ABBREVIATION}

spf: sun protection factor, rf: range factor, uv: ultraviolet, tlc: thin layer chromatography, o/w: oil on water, cp: centipoise

\section{AUTHORS CONTRIBUTIONS}

All the authors have contributed equally

\section{CONFLICT OF INTERESTS}

Declared none

\section{REFERENCES}

1. Afaq F, Mukhtar H. Effects of solar radiationon cutaneous detoxification pathways. J Photochem Photobiol B 2001;63:61-9.

2. Tebbe B. Relevance of oral supplementation with antioxidants for prevention and treatment of skin disorders. Skin Pharmacol Physiol 2001;14:296-302.

3. Sopyan I, Gozali D, Tiassetiana S. Formulation of tomato extracts (Solanumlycopersicum L.) as a sunscreen lotion. Nat J Phys Pharm Pharmacol 2018;8:453-8.

4. Baumann L. Cosmetics and skin care in dermatology. Dalam: Fitzpatrik's dermatology in general medicine. The McGraw-Hill Companies, Inc., New York; 2008. p. 2357-9.

5. Caswell M. Formulating for sun: sunscreen formulation and testing. US Allured Publ Corp 2006. p. 201.

6. Ansel HC. Pengantar bentuk sediaan farmasi. Penerjemah Farida Ibrahim J kt UnivIndones; 1989EdIV. p. 245-9.

7. Couteau C, Paparis E, El-Bourry-Alami S, Coiffard LJM. Influence on SPF of the quantity of sunscreen product applied. Int J Pharm 2012;437:250-2.

8. Turkoglu M, Cigirgil N. Evaluation of black tea gel and its protection potential against UV. Int J Cosmet Sci 2007; 29:437-42.

9. Yuliani SH. Optimasi kombinasi campuran sorbitol, gliserol, dan propilenglikol dalam gel sunscreen ekstrak etanol curcuma mangga. Maj Farm Indones 2010;21:83-9.

10. Young AR, Claveau J, Rossi AB. Ultraviolet radiation and the skin: photobiology and sunscreen photoprotection. J Am Acad Dermatol 2017;76(3 Suppl 1):100-9.

11. Kale MA, Bindu SM, Khadkikar P. Role of antioxidant and nutrition in oxidative stress: a review: Int J Appl Pharm 2015;7:1-4.

12. Ling TC, Faulkner C, Rhodes LE. A questionnaire survey of attitudes to and usage of sunscreens in northwest England. Photodermatol Photoimmunol Photomed 2003;19:98-101.

13. Duarah S, Pujari K, Durai RD, Narayanan VHB. Nanotechnologybased cosmecutical: a review. Int J Appl Pharm 2016;8:8-12.

14. Petro AJ. Correlation of spectrophotometric data with sunscreen protection factors. Int J Cosmet Sci 1981;3:185-96.

15. Aulton ME, Wells TI. Pharmaceutics, the science of doges form design, churchill livingstome. Vingstone, London: Churchill Livingstone; 1988. p. 243

16. Hockmeyer HH. Understanding high-viscosity mixing. Adhes Sealants Ind 2000;7:44-50.

17. Lowe NJ, Friedlander J. Sunscreens: rationale for use to reduce photodamage and phototoxicity. Sunscreens Dev Eval Regul Asp; 1997. p. 35-58.

18. Dutra EA, Oliveira DAG da C, Kedor Hackmann ERM, Santoro MIRM. Determination of sun protection factor (SPF) of sunscreens by ultraviolet spectrophotometry. Rev Bras Cienc Farm 2004;40:381-5.

19. Lachman L, Lieberman H, Kanig JL. Teoridanpraktek Farmasilndustri II. 3rd edition. Terjemahan Siti Suyatmi, Jakarta: UI Press; 2008. p. 210. 